\title{
Phenotyping chickpeas and pigeonpeas for adaptation to drought
}

\author{
H. D. Upadhyaya ${ }^{1}{ }^{*}$, J. Kashiwagi ${ }^{2}$, R. K. Varshney ${ }^{1}$, P. M. Gaur ${ }^{1}$, K. B. Saxena ${ }^{1}$, L. Krishnamurthy ${ }^{1}$, C. L. L. \\ Gowda $^{1}$, R. P. S. Pundir ${ }^{1}$, S. K. Chaturvedi ${ }^{3}$, P. S. Basu ${ }^{3}$ and I. P. Singh ${ }^{3}$
}

${ }_{1}^{1}$ International Crops Research Institute for the Semi Arid Tropics, Hyderabad, India

${ }^{2}$ Crop Science Laboratory, Graduate School of Agriculture, Hokkaido University, Sapporo, Japan

3 Indian Institute of Pulses Research, Kanpur, India

\section{Edited by:}

Jean-marcel Ribaut, Generation Challenge Programme, Mexico

\section{Reviewed by:}

Sean Cutler, University of California

Riverside, USA

Sona Pandey, Donald Danforth Plant

Science Center, USA

\section{${ }^{*}$ Correspondence:}

H. D. Upadhyaya, International Crops

Research Institute for the Semi Arid

Tropics, Hyderabad, 502324 Andhra

Pradesh, India.

e-mail: h.upadhyaya@cgiar.org
The chickpea and pigeonpea are protein-rich grain legumes used for human consumption in many countries. Grain yield of these crops is low to moderate in the semi-arid tropics with large variation due to high GxE interaction. In the Indian subcontinent chickpea is grown in the post-rainy winter season on receding soil moisture, and in other countries during the cool and dry post winter or spring seasons. The pigeonpea is sown during rainy season which flowers and matures in post-rainy season. The rainy months are hot and humid with diurnal temperature varying between 25 and $35^{\circ} \mathrm{C}$ (maximum) and 20 and $25^{\circ} \mathrm{C}$ (minimum) with an erratic rainfall. The available soil water during post-rainy season is about 200-250 mm which is bare minimum to meet the normal evapotranspiration. Thus occurrence of drought is frequent and at varying degrees. To enhance productivity of these crops cultivars tolerant to drought need to be developed. ICRISAT conserves a large number of accessions of chickpea $(>20,000)$ and pigeonpea $(>15,000)$. However only a small proportion $(<1 \%)$ has been used in crop improvement programs mainly due to non-availability of reliable information on traits of economic importance. To overcome this, core and mini core collections ( $10 \%$ of core, $1 \%$ of entire collection) have been developed. Using the mini core approach, trait-specific donor lines were identified for agronomic, quality, and stress related traits in both crops. Composite collections were developed both in chickpea (3000 accessions) and pigeonpea (1000 accessions), genotyped using SSR markers and genotype based reference sets of 300 accessions selected for each crop. Screening methods for different drought-tolerant traits such as early maturity (drought escape), large and deep root system, high water-use efficiency, smaller leaflets, reduced canopy temperature, carbon isotope discrimination, high leaf chlorophyll content (drought avoidance), and breeding strategies for improving drought tolerance have been discussed.

Keywords: carbon isotope, composite collection, core collection, genetic diversity, mini core collection, reference set, root traits, SSR markers

\section{GENERAL INFORMATION}

\section{IMPORTANCE OF CHICKPEAS AND PIGEONPEAS IN THE HUMAN DIET}

Chickpeas (Cicer arietinum $\mathrm{L}$ ) are the fourth largest grain legume crop in the world, with a total production of 10.9 million tons from an area of 12.0 million ha and a productivity of $0.91 \mathrm{tha}^{-1}$ (Food and Agriculture Organization of the United Nations (FAO, 2010b)). Large variations in chickpea yield are reported, ranging from 0. $45 \mathrm{tha}^{-1}$ in Tanzania to $1.67 \mathrm{tha}^{-1}$ in Canada. Chickpea productivity records in the last four decades reveal an interesting trend: productivity consistently increased in India and Mexico while it declined in Turkey, Pakistan, and Iran.

The global production of pigeonpeas (Cajanus cajan $\mathrm{L}$ ) is 3.7 million tons from an area of 4.8 million ha with a productivity of $0.77 \mathrm{tha}^{-1}$. Large variations in pigeonpea yields from $0.3 \mathrm{tha}^{-1}$ in Haiti to $1.2 \mathrm{tha}^{-1}$ in The Philippines are reported. Pigeonpeas are grown as a field and as a backyard crop in several countries, but as a field crop only in 21 countries (FAO, 2010b).
Both chickpeas and pigeonpeas are important grain legumes grown for their protein-rich seeds used in human consumption, for their ability to restore and maintain soil fertility by nitrogen fixation, and for their suitability to fit very well into various cropping patterns. Globally, over $90 \%$ of chickpeas and pigeonpeas are produced and consumed in Asia. Chickpea seeds contain 23\% protein, $64 \%$ carbohydrates, $5 \%$ fat, $6 \%$ crude fiber, $6 \%$ soluble sugar, and 3 percent ash (William and Singh, 1987), whereas pigeonpea seeds contain $20.5 \%$ protein, $64.2 \%$ carbohydrates, $6.8 \%$ lysine, $3.8 \%$ fat, $5 \%$ fiber, and $4.2 \%$ ash (Faris and Singh, 1990).

\section{CHARACTERIZATION OF GROWING ENVIRONMENTS}

Chickpeas are largely grown in arid and semi-arid environments in Asia and Africa, with more than $80 \%$ of the annual rainfall occurring during the rainy season (June-September). The rainfall variability within the region is usually high, leading to varying intensities of drought. In the Indian subcontinent, chickpeas 
are grown during the post-rainy season. In northern Pakistan, Afghanistan, Iran, the Middle East, and Mediterranean Europe, they are cultivated during the wetter winter months or, where snow occurs, during the cool dry springtime period, wherein more than $70 \%$ of the annual precipitation (i.e., snow plus rain) falls during the 5-6 months from November/December to April, with summers typically dry and warm (Khan, 1980). Although the mean total annual precipitation throughout the region rarely exceeds $500 \mathrm{~mm}$, it is conserved and used rather effectively during the cool winter season by a crop that has a relatively small evapotranspiration requirement $(200-250 \mathrm{~mm})$. Mean annual air temperatures are often cooler than $20^{\circ} \mathrm{C}$, except in some areas where the rainfall distribution is bimodal.

The alluvial soils (Entisols) in northwest India and Nepal may retain up to $200 \mathrm{~mm}$ of available water in a $120 \mathrm{~cm}$ deep soil profile. Over similar depths, the black cotton soils (Vertisols) of the Indian subcontinent have the potential to store $250 \mathrm{~mm}$ of available water. Potential evapotranspiration demand during the 5-6 month period from October/November to March is typically within the range $200-300 \mathrm{~mm}$ for most chickpea-growing areas in the region. Thus, chickpeas are usually grown under stored residual soil moisture with the moisture receding to deeper soil layers with the age of the plants, leading to terminal drought stress. The intensity and the timing of the stress can, of course, vary depending on the previous rainfall, soil type, crop duration, and crop growth.

Pigeonpeas are commonly sown during the rainy season and flower and mature in the post-rainy season. The rainy months are hot, average diurnal air temperatures varying between 25 and $35^{\circ} \mathrm{C}$, with daily maximum values typically close to $35^{\circ} \mathrm{C}$ and warm nights $\left(20-25^{\circ} \mathrm{C}\right)$. There can be large gaps between the two rainfall events leading to spells of intermittent drought stress. Pigeonpeas are grown on a wide range of soils in the tropics and subtropics including Entisols, Vertisols, Alfisols, Inceptisols, Ultisols, and Oxisols, with a wide variation in water-holding capacity. Both Entisols and Vertisols are generally deep and hold more than $200 \mathrm{~mm}$ of plant-available water to a depth of $1.5 \mathrm{~m}$ at the end of the rainy season, whereas Alfisols are usually less than $1 \mathrm{~m}$ deep and hold less than $90 \mathrm{~mm}$ plant-available water to a depth of $1 \mathrm{~m}$ (Reddy and Virmani, 1981). The crop grows well on Entisols, but suffers moisture deficits of different intensities as intermittent and/or terminal drought on Alfisols and Inceptisols.

Clearly, there is a need to match the duration of the soil moisture availability to that of the genotype duration for maximizing productivity in any given environment.

\section{GENETIC AND GENOMIC RESOURCES Germplasm in CGIAR and NARS genebanks}

Plant genetic resources are the most valuable among all of the natural resources. The widespread cultivation of modern and high-yielding cultivars has posed a great threat to the reservoir of local plant biodiversity that has evolved over millennia. To safeguard this diversity, large-scale collecting and conservation efforts have been made in recent years, resulting in the assembly of more than 7 million accessions held worldwide in over 1750 genebanks of the Consultative Group on International Agricultural Research (CGIAR) or of national agricultural research systems (NARS; FAO, 2010a). There are over 98,000 chickpea accessions in genebanks, predominantly preserved at the International Crops Research Institute for the Semi-Arid Tropics (ICRISAT) and the International Center for Agricultural Research in the Dry Areas (ICARDA). There are 28,000 pigeonpea accessions in genebanks, with ICRISAT holding 13, 632 accessions. In addition, substantial numbers of chickpea and pigeonpea accessions are stored at the National Bureau of Plant Genetic Resources (NBPGR), New Delhi, India. The other two genebanks holding large collection of chickpea are the United States Department of Agriculture (USDA) Regional Plant Introduction Station, Pullman, Washington State and the Australian Temperate and Field Crops Collection (ATFCC), Victoria, Australia. These genebanks also maintain ca 900 wild relatives of chickpeas and ca 670 of pigeonpeas. In addition, 269 chickpea and 1619 pigeonpea elite germplasm lines have also been registered in the genebanks.

\section{Assessing genetic diversity for phenotypic traits}

The assessment of diversity in germplasm is important to plant breeders for crop improvement and to genebank curators for efficient and effective management of their collections. A large collection of chickpea germplasm has been characterized for a number of morphophysiological and reproductive traits at ICRISAT, Patancheru, India. Diversity assessment, based on 16,820 accessions and 13 traits, revealed an interesting trend, namely significant differences in means and heterogeneous variances for agronomic traits among regions. Accessions from Africa were earliest to flower, and those from Southeast Asia shortest in stature. Cluster analysis delineated two regional clusters consisting of Africa and South and Southeast Asia in the first, and the Americas, Europe, West Asia, the Mediterranean, and East Asia in the second (Upadhyaya, 2003).

Diversity assessment in pigeonpeas (based on 26 traits in 11,402 accessions) also revealed significant differences in means and heterogeneous variances among regions. Accessions from Oceania were conspicuous by their short growth duration, reduced plant height, fewer branches, pods with fewer seeds, smaller seed size, and lower seed yields. In contrast, accessions from Africa were of longer duration, taller, with multi-seeded pods, and larger seeds. Cluster analysis delineated three clusters: cluster 1 including accessions from Oceania; cluster 2 from India and adjacent countries, and cluster 3 from Indonesia, Thailand, Philippines, Europe, Africa, America, and Caribbean countries (Upadhyaya et al., 2005).

\section{Core and mini core collections to sample representative diversity in the entire collection}

The main reason for the low use of germplasm in crop improvement programs is the lack of information on a large number of the accessions, particularly for traits of economic importance which display a great deal of genotype-by-environment interaction (GEI). Frankel (1984) introduced the concept of developing a core collection, which consist of about $10 \%$ of the entire collection and represent at least $70 \%$ of the genetic variability of the entire collection (Brown, 1989) as a gateway to the enhanced utilization of germplasm in breeding. Core collections of chickpeas and pigeonpeas have been reported (Upadhyaya et al., 2001; Reddy et al., 
2005). However, it soon became evident that developing core collections would not solve the problem of low use of germplasm, because even the core collection could still be large. To overcome this, Upadhyaya and Ortiz (2001) proposed the "mini core collection" concept (consisting of $10 \%$ of the core or $1 \%$ of the entire germplasm), and developed mini core subsets in chickpeas and pigeonpeas (Upadhyaya and Ortiz, 2001; Upadhyaya et al., 2006b).

Core and mini core collections to identify trait-specific germplasm Core and mini core subsets provide easy access to the wider spectrum of germplasm collections for discovering useful variation for breeding and genomics applications. When evaluated, new sources of variation have been reported in chickpeas for, for example, high yield (Upadhyaya et al., 2007a), early maturity (Upadhyaya et al., 2007b), large seed size, drought and salinity tolerance (Serraj et al., 2004a,b; Kashiwagi et al., 2005, 2006a), and disease resistance (Pande et al., 2006). In pigeonpeas, new sources of early maturity with high yield (Upadhyaya, unpublished) and salinity tolerance have been discovered (Srivastava et al., 2006).

\section{Polymerase chain reaction-based markers, genotypic diversity, and genetic maps}

Development and use of polymerase chain reaction (PCR)-based molecular markers and genetic maps in chickpeas started as early as 1990 (Gaur and Slinkard, 1990). Subsequently, several hundred simple sequence repeat (SSR) markers have been developed in chickpeas (Varshney et al., 2007). The majority of these markers have been mapped in two inter-specific mapping populations: C. arietinum ICC $4958 \times$ C. reticulatum PI 489777 (Winter et al., 1999, 2000; Pfaff and Kahl, 2003) and C. arietinum FLIP 84-92C × C. reticulatum PI 599072 (Tekeoglu et al., 2002), and genetic linkage maps of varying genome coverage have been reported.

Molecular markers in pigeonpeas were used to study genetic diversity (Nadimpalli et al., 1994; Ratnaparkhe et al., 1995). The level of polymorphism among wild species was high, while little polymorphism was detected within $C$ cajan accessions. Recently, amplified fragment length polymorphism (AFLP) and diversity arrays technology (DArT) analysis have been conducted on a few cultivars and wild species, with similar results of low polymorphism being observed among pigeonpea cultivars (Panguluri et al., 2006; Yang et al., 2006).

Upadhyaya et al. (2006a) developed a composite collection of chickpea (3,000 accessions), representing the entire spectrum of genetic diversity present in ICRISAT and ICARDA genebanks. They genotyped the 3,000 accessions using high-throughput assay and 50 SSR markers. Data on two markers (TA28 and TR2) were not used in the analysis and only a dataset of 48 SSR loci on 2,915 accessions (with less than 3.25\% missing data) of the composite collection was used to study structure and diversity and thereby identify a reference set of the 300 most diverse accessions (Upadhyaya et al., 2008). This composite collection showed rich allelic diversity (1,683 alleles, and 35 alleles per locus, with 935 rare alleles, 748 common alleles, and gene diversity from 0.534 to 0.975 ), and a number of group-specific unique alleles (114 in Kabuli, 297 in Desi, 69 in wild Cicer, 114 in Mediterranean, 114 in West Asia, and 117 in South and Southeast Asia groups). The Kabuli group was more genetically diverse than other types. Only four alleles in pea-shaped chickpeas differentiated them from other biological groupings. South and Southeast Asia and West Asia groups shared 74 common alleles, Mediterranean and South and Southeast Asia groups shared 33, and Mediterranean and West Asia groups shared 38. Desi and Kabuli types shared 436 alleles. DARwin structure analysis revealed that Desi and Kabuli chickpeas formed two distinct clusters. A reference set consisting of 300 accessions captured $78 \%(1,315$ alleles) of allelic richness from the composite collection $(1,683$ alleles).

A pigeonpea composite collection of 1,000 accessions was developed that has been profiled using 20 SSRs and highthroughput assays at ICRISAT. After quality control, a complete dataset of 20 SSRs on 952 accessions ( $<3 \%$ missing data point) was used to dissect the structure and diversity in the composite collection and for the formation of a reference set. A total of 197 alleles were detected in the composite collection, of which 115 were rare and 82 common alleles. Gene diversity varied from 0.002 to 0.726. Biologically, group-specific unique alleles were 60 in wild types and 64 in cultivated types. Simple matching allele frequencybased distance matrix was used to identify a reference set of the 300 most diverse accessions, capturing 95\% (187 alleles) of the 197 alleles of the composite collection (952 accessions). The reference set will be profiled with additional markers and extensively phenotyped for traits of economic importance to identify accessions for beneficial traits for utilization in pigeonpea breeding and genomics.

\section{RELEVANT RESULTS PUBLISHED IN THE AREA OF DROUGHT ADAPTATION}

Improving the drought tolerance of crop plants has been a difficult challenge under rain-fed environments because: (i) the rainfall received and the frequency of rainfall events vary among the seasons/years and locations; and (ii) large genotype-by-season or genotype-by-location interactions mask the genetic variation of yield. It is difficult to develop phenotypic screens for intermittent drought tolerance since the timing and intensity of this type of drought are fairly unpredictable, whereas screening for terminal drought has been successful in many crop plants (Turner, 1986; Subbarao et al., 1995). The strategies through which crops cope with soil water deficit can be categorized into three groups (Loomis and Connor, 1992): (i) drought escape in which the crops try to complete their reproductive growth before the soil water deficit becomes too severe; (ii) drought avoidance where the crops either minimize the water loss from their tissues or enhance water absorption even under drought conditions; and (iii) drought tolerance where the crops enhance the physical and/or physiological capability of their cells to continue metabolism at low leaf water status.

\section{METHODOLOGY BREEDING STRATEGY Chickpeas}

Terminal drought escape through early phenology (shortduration) has been the most successful breeding strategy in chickpeas (Gaur et al., 2008). The number of days taken from sowing 
to flowering initiation can be recorded easily, providing a good indication of the succeeding phenological traits (days to podding and to maturity), since these traits are intercorrelated. Pundir et al. (1988) reported a range from 33 to 107 days for time to $50 \%$ flowering in a collection of 12,018 accessions. This is a wide range and provides good scope for developing cultivars with the desired earliness. In segregating generations, plants that flower early, for instance in 25-30 days at ICRISAT-Patancheru, are tagged and their progenies are evaluated further. Selection for time to flowering is effective even in early segregating generations, since the trait is recessive and controlled by a few major genes (Or et al., 1999; Kumar and van Rheenen, 2000). Several early maturing high-yielding cultivars have been developed, for example, ICCV 2 (released in India, Sudan, and Myanmar), ICCV 92311, JGK 1, and KAK 2 (released in India) and ICCV 92318 (released in Ethiopia) in Kabuli types, and ICCC 37, JG 11, and ICCV 93954 (released in India) and ICCV 88202 (released in Australia, Myanmar and India) in Desi types. Adoption of early maturing varieties such as KAK 2, JG 11, Vihar etc., has shown high impact on enhancement of the chickpea area under cultivation and productivity in shortseason environments such as Myanmar (Than et al., 2007) and southern India (Gaur et al., 2008).

It has been possible to develop breeding lines that mature earlier than both the parents by accumulating earliness genes from the two parents. For example, the super-early line ICCV 96029, which flowers in about 24 days at Patancheru, was developed from a cross between two early lines, ICCV 2 and ICCV 93929, which flower in 30 and 32 days (Kumar and Rao, 1996). Super-early lines have further expanded opportunities for cultivation of chickpeas in areas and cropping systems where the cropping window available for chickpeas is narrow and in specific situations where early podding is highly desired, for example when immature grains are used as vegetables (Sandhu et al., 2007).

The prolific root system in chickpeas contributes to grain yield under terminal drought conditions (Kashiwagi et al., 2006a). Reports on the relationship of other morphophysiological traits to grain yield under drought conditions are variable. Thus, breeding efforts using any of these traits as criteria for drought tolerance are few. Although the importance of a prolific root system in terminal drought tolerance is well recognized, only limited efforts have been made to breed for improved root traits. This is because screening for root traits is a destructive and labor intensive process, and difficult to use in large segregating populations.

Combining different drought resistance mechanisms is a potential strategy for enhancing levels of drought resistance. Efforts have been made to combine the large root trait with few leaflets, and breeding lines have been developed combining these traits (Saxena, 2003). However, no information is available on their drought tolerance.

It is well recognized that molecular markers linked to major genes controlling root traits can facilitate marker-assisted breeding (MAB) for those traits. A major quantitative trait locus (QTL) contributing one third of the variation for root length and root biomass has been identified (Chandra et al., 2004) and efforts are being made to identify additional QTLs for root traits. MAB for root traits in chickpeas is in progress.

\section{Pigeonpeas}

Traditional long- and medium-duration pigeonpea landraces have evolved under, and have apparently adapted to, terminal drought stress conditions. However, studies show that prevalence of drought during the reproductive phase usually reduces grain yield in pigeonpeas (Chauhan et al., 1992). This is more apparent in environments closer to the equator where evapotranspiration is high. Since a large spectrum of maturity is now available in pigeonpeas, the development of genotypes with the duration that matches well with the duration of soil moisture availability is the first line of defense against terminal drought stress. Another strategy may be to select the single plants from segregating populations that show good yield in hotspots for terminal drought conditions. Furthermore, opting for a shorter duration cultivar than those traditionally used in a region does not necessarily mean sacrificing yield potential, since even extrashort-duration cultivars can produce yields above $2.5 \mathrm{t} \mathrm{ha}^{-1}$ (Nam et al., 1993).

Hybrids in most crops have been found to perform well under moisture stress conditions. Two pigeonpea hybrids, ICPH 8 and ICPH 9, exhibited higher yield levels than controls irrespective of soil moisture regimes. This suggests that pigeonpea hybrids have the potential to perform well in both dry as well as optimum soil moisture environments (Saxena et al., 1997). This may be related to their superior ability to maintain relative water content (Lopez et al., 1994).

\section{TRIAL PLANNING}

Segregating populations originating from hybridization between drought-tolerant and susceptible lines should be grown under drought stress situations, and may be advanced following the single seed descent method until the lines attain a good level of phenotypic uniformity. The advanced lines should be evaluated for at least 3 years to assess their yield potential under terminal drought stress conditions. In the first year, all the lines along with controls should be grown in a preliminary trial with two to three replications on a small plot size, using appropriate experimental designs. In the second and third years, the selected lines along with controls should be promoted to advanced and elite trials, respectively, and should be evaluated multilocationally, preferably with a higher number of replications and a bigger plot size. These trials should be grown under rain-fed conditions (hotspot locations) prone to terminal drought. The entries that outperform (at least by $10 \%$ ) under drought stress situation may be selected for further evaluation. The best performing drought-tolerant lines should be involved in a more detailed study to dissect the genetic, physiological, and molecular basis of drought tolerance. In all of the trials, soil and climate data must be recorded to document the contribution of these variables to the performance of test entries and also to explain GEI.

\section{DROUGHT STRESS MANAGEMENT AND CHARACTERIZATION}

Rainout shelters are designed to protect a certain area of the land against receiving precipitation so that a controlled drought stress can be imposed on that area. Static and moveable rainout shelters have been constructed, with the latter having either 
automatic/motorized or manual versions. The automatic version is activated to move over the protected plot by a rain sensor and an electronic drive system. The manual version is moved either by manually switching the drive on or by manually pushing it over the protected plot. The manually handled rainout shelters are lightweight and therefore cheaper to construct. ICRISAT has designed manually driven rainout shelters for use in drought research (Chauhan et al., 1997). One unit made from gabled metal frames covered by polythene sheets is $7.5 \mathrm{~m}$ wide, $15 \mathrm{~m}$ long, and $2 \mathrm{~m}$ high (at the mid-point).

Line-source sprinkler irrigation (Hanks et al., 1976) is the most common method to create a moisture gradient to screen for mid- and terminal drought stress. The plot nearest to the sprinkler head serves as a control (fully irrigated). The amount of water then decreases as the distance of the plot from the sprinkler head increases, allowing increasing intensities of drought stress. Catch cans (plastic buckets) are kept on each plot to measure the amount of water applied by sprinklers. A neutron probe (Model 2651 Troxler Electronic Laboratories Inc, USA), is used to assess the soil moisture at various depths at regular interval through access tubes buried up to the desired depth. However, neutron probe readings need to be calibrated, at least once, against the gravimetrically estimated soil moisture content. The readings derived from calibration of the count ratio of the neutron moisture meter are further converted into volumetric moisture content. A summation of volumetric water present at each soil depth, up to the maximum known depth of root penetration, would provide the amount of available soil water $($ in $\mathrm{cm}$ ) in the whole soil profile.

When to impose drought stress - as mid-season or terminal drought - depends upon the crop phenology, guided mainly by the crop duration. In general, test materials are grouped according to similar maturity and then subjected to drought stress. Midseason drought is imposed at flowering, while terminal drought is imposed during the post anthesis period (preferably 30-40 days prior to maturity). Water is withheld during this period and the drought response is measured against the fully irrigated control.

\section{PLANT WATER STRATEGY \\ Drought escape}

Crops that mature early have a better chance to escape terminal drought. Even in segregating populations, it is easy to score for early maturity, since the number of days taken to flowering correlates fairly well with crop phenology (Murfet and Reid, 1985; Kumar and Abbo, 2001). A faster rate of partitioning has been shown to be associated with drought tolerance, permitting a relatively higher biomass at flowering and escaping part of the terminal drought periods (Krishnamurthy et al., 1999). This can be assessed in any conventional field studies. The traits to measure under drought stressed environments are vegetative and reproductive growth periods, shoot biomass at 50\% flowering, and shoot biomass and grain yield at maturity. Similar sets of data under optimally irrigated conditions as well as under drought would permit comparison of the rate of partitioning between the different environments (Krishnamurthy et al., 1999).

\section{Drought avoidance}

Stomatal conductance, root traits, water-use efficiency (WUE), and osmotic adjustment (OA) are some important mechanisms allowing selection for drought avoidance. Stomatal conductance regulates transpiration activity through which the plant can minimize water loss under drought stress conditions. It can be estimated by using a gas exchange system such as LI-COR Biosciences' LI-6400 portable photosynthesis system. However, it is timeconsuming and, hence, not suitable for large-scale phenotyping of populations - a requisite in molecular breeding approaches. As canopy temperature is a consequence of stomatal activity, it can serve as a proxy to estimate stomatal activity. Plant canopy temperature differences can be quantified using an infra-thermo camera (Figures 1A,B) and such differences have been shown to correlate reasonably well with the transpiration status in rice, potatoes, wheat, and sugar beet (Fukuoka, 2005). This sophisticated device can record the thermal digitized image of the plant canopy within a short time (1 $\mathrm{min})$, thus allowing phenotyping for transpiration (stomatal conductance) in large populations. Now with the availability of a macro program, it is also possible to remove the image background (Figures 2A,B) of the soil surface (or the soil reflection) before estimating the canopy area alone. These images are also readable through the Macro for the estimation of the range and the extent of canopy fraction with a specific temperature as well the average temperature of the whole canopy (Figures 3A,B) and phenotype chickpeas and pigeonpeas for canopy temperature or transpiration status.

Variations in root traits have been associated with enhanced drought tolerance in some crops (Subbarao et al., 1995; Kashiwagi et al., 2005). However, it is very cumbersome to screen for root
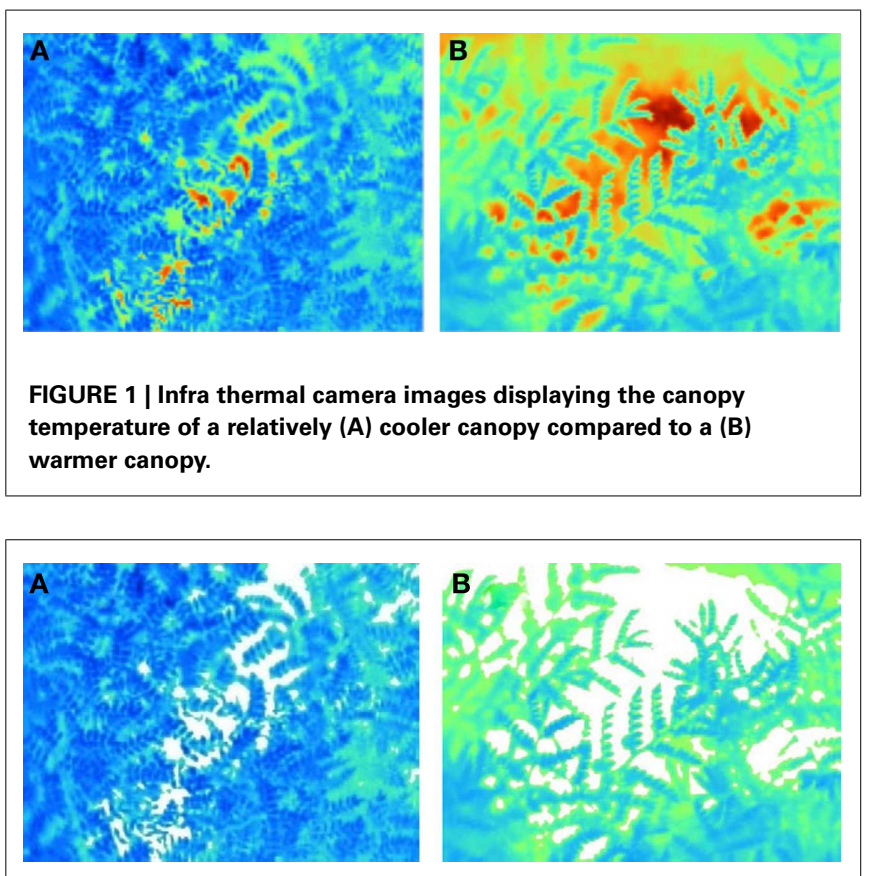

FIGURE 2 | Infra thermal camera images after removal of the background soil reflection and retaining the canopy image alone of a relatively $(A)$ cooler canopy compared to a (B) warmer canopy. 
traits under field conditions. To overcome this limitation, a cylinder culture system (using polyvinyl chloride (PVC) pipes $18 \mathrm{~cm}$ in diameter and $120 \mathrm{~cm}$ tall) has been developed that allows screening of large amounts of chickpea germplasm for root characteristics (root length density and rooting depth). With this system, the sampling efficiency can be improved dramatically up to about 25 profiles worker ${ }^{-1}$ day $^{-1}$, which is approximately 7.5 times faster than field sampling. These observations correlate well with the field observations $(r=0.62, p<0.05)$ when cylinders are packed with Vertisols premixed to $70 \%$ field capacity soil moisture. Further, once the roots have been extracted, the root length can be measured quickly in a sophisticated image analysis system. Thus, platform scanners can each scan more than 150 samples per day, and the powerful image analysis software WinRhizo helps measure root length with a capacity of more than 500 images per day. This system is capable of providing reliable root phenotyping data for any large size populations. However, with the cylinder system, information cannot be obtained on root architecture or branching pattern. An acrylic root rhizobox method would be the ideal way to grow the plants in large populations and the image analysis systems could be applied directly to capture the image digitally and analyze it. Currently, the rhizobox is being optimizing at ICRISAT for both chickpeas (Figure 4) and pigeonpeas.

Recent work at ICRISAT has shown that the variation in root length density in the surface layer $(15-30 \mathrm{~cm}$ depth) also matters and shown to contribute to the seed yield both under moderate to severe drought environments in Vertisols (Kashiwagi et al., 2006a; Table 1). This yield contributory effect was explained as a consequence of rapid absorption of soil water by the plants of a fraction of soil water which otherwise would have been lost due to evaporation. A wide range of diversity in rooting profile and

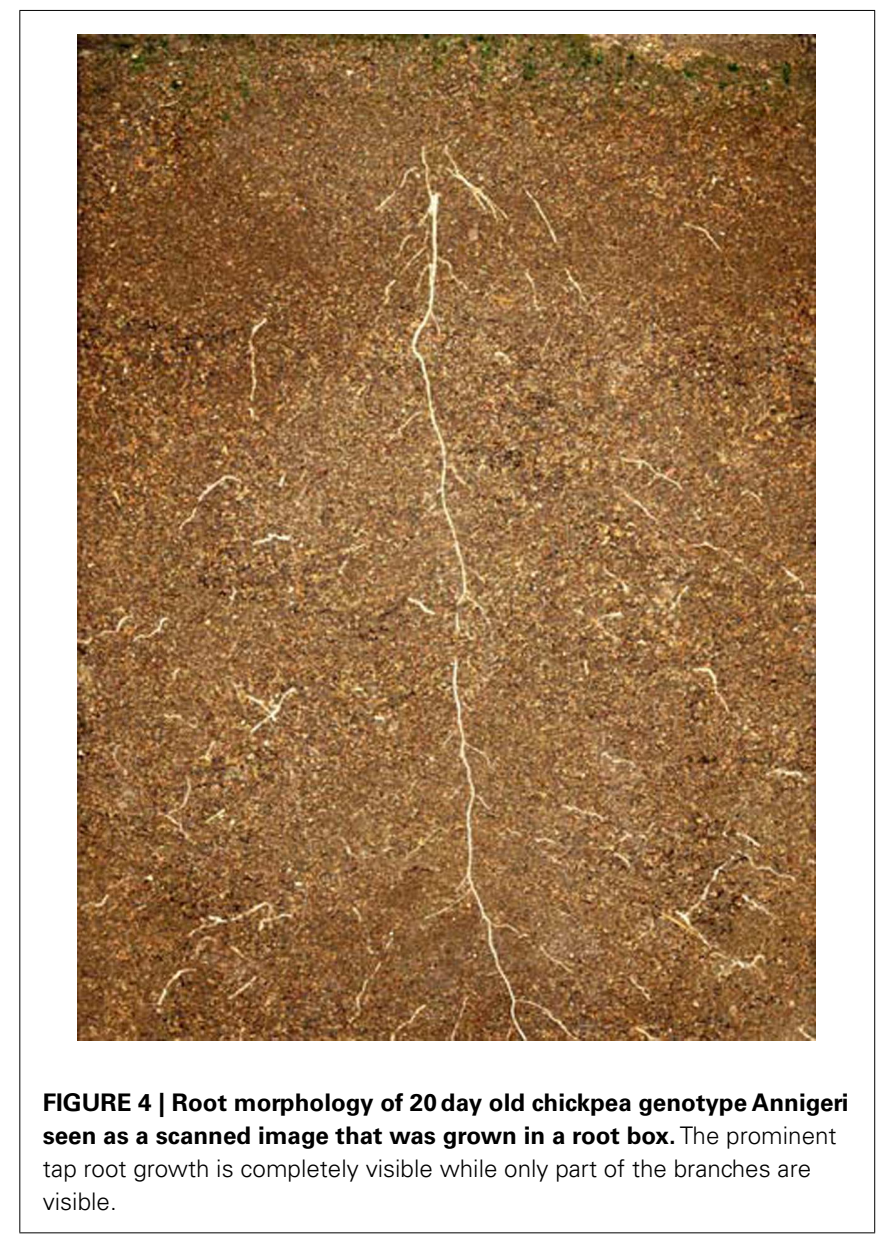

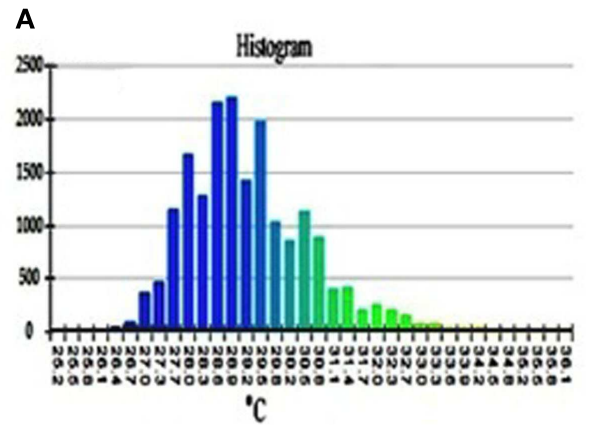

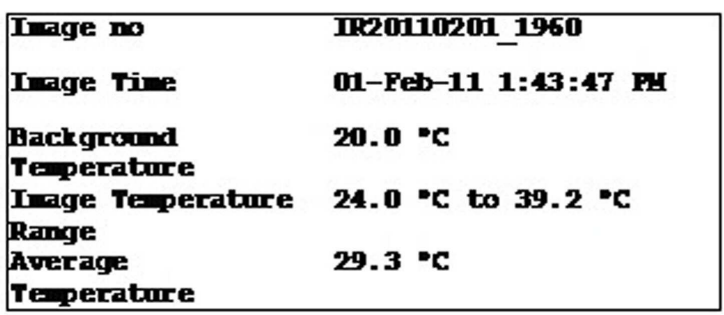
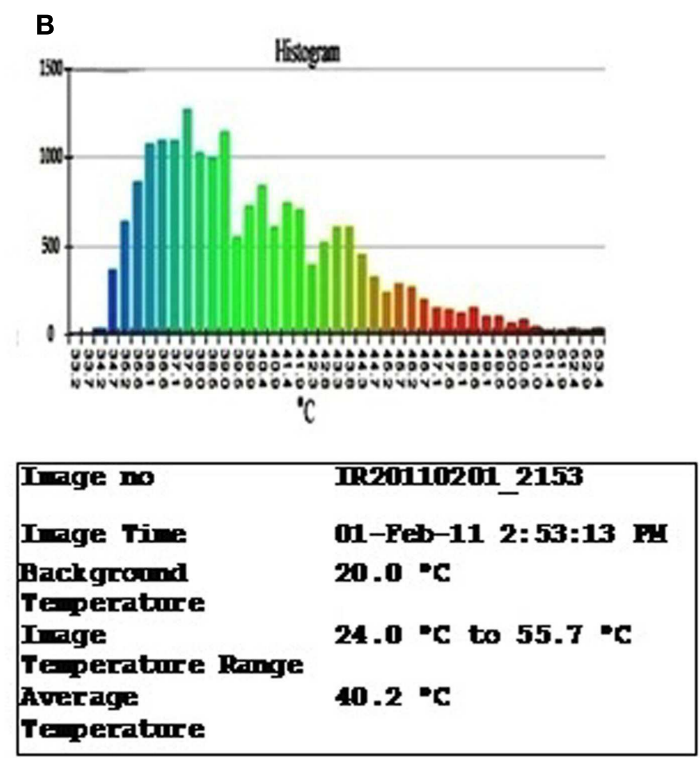

FIGURE 3 | Histograms and the details of the image displaying the extent canopy size under a class of temperature, of the Infra thermal camera images of a relatively (A) cooler canopy compared to a (B) warmer canopy. 
Table 1 | Correlation coefficients among the root length densities (total and layer-wise) observed at 35 days after sowing and the seed yield of 12 cultivated chickpea genotypes grown in a Vertisol field during 2000-01 (moderate drought year) and 2001-02 (severe drought year) post-rainy seasons.

$\begin{array}{lllll}\text { RLD } & \text { RLD } & \text { RLD } & \text { RLD } & \text { RLD } \\ (0-15) & (15-30) & (30-45) & (45-60) & \text { tot }\end{array}$

\begin{tabular}{lrlllll}
\hline 2000-2001 FIELD TRIAL & & & & \\
RLD 15-30 & 0.381 & & & & \\
RLD 30-45 & -0.024 & $0.645^{*}$ & & & \\
RLD 45-60 & 0.059 & $0.684^{*}$ & $0.935^{* *}$ & & \\
RLD tot & 0.532 & $0.883^{* *}$ & $0.797^{* *}$ & $0.838^{* *}$ & \\
YLD $\left(\mathrm{g} \mathrm{m}^{-2}\right.$ ) & 0.344 & $0.699^{*}$ & 0.406 & 0.405 & $0.613^{*}$
\end{tabular}

$\begin{array}{lllllll}\text { 2001-2002 FIELD TRIAL } & & & & \\ \text { RLD 15-30 } & 0.854^{* *} & & & & \\ \text { RLD 30-45 } & 0.757^{* *} & 0.785^{* *} & & & \\ \text { RLD 45-60 } & 0.577 & 0.528 & 0.819^{* *} & & \\ \text { RLD tot } & 0.943^{* *} & 0.915^{* *} & 0.909 * * & 0.761^{* *} & \\ \text { YLD }\left(\mathrm{g} \mathrm{m}^{-2}\right) & 0.442 & 0.718^{* *} & 0.779 * * & 0.576^{*} & 0.659^{*}\end{array}$

RLD 0-15= Root length density at $0-15 \mathrm{~cm}$ soil depth.

RLD 15-30= Root length density at $15-30 \mathrm{~cm}$ soil depth.

RLD 30-45= Root length density at $30-45 \mathrm{~cm}$ soil depth

RLD 45-60= Root length density at 45-60 cm soil depth

$R L D$ tot $=$ Average root length density at the $0-60 \mathrm{~cm}$ profile.

$Y L D\left(\mathrm{~g} \mathrm{~m}^{-2}\right)=$ Grain yield $\left(\mathrm{g} \mathrm{m}^{-2}\right)$ at maturity.

* Significant at $P=0.05$ and ${ }^{*}$ Significant at $P=0.01$.

abundance has been noted in chickpeas: ICC 4958 and ICC 8261 have prolific and deeper roots, and ICC 1882 and ICC 283 have small and shallow roots (Kashiwagi et al., 2005). In pigeonpeas, a deeper rooting system is likely to have the advantage of sustaining better growth, even under medium and long-duration drought environments (Chauhan et al., 1992). In contrast, many highyielding short-duration pigeonpea varieties that were developed to fit into sole cropping systems have shallow root systems and are unable to extract soil water effectively beyond $50 \mathrm{~cm}$ (Subbarao et al., 2000).

Water-use efficiency has been used to select for drought tolerance in many crops (Farquhar et al., 1982; Hubick et al., 1986; Wright et al., 1988, 1994). Although improved WUE under drought environments did not always result in better seed yield, it could improve biomass production (White et al., 1990). Phenotyping for WUE in chickpeas and pigeonpeas could be achieved by gravimetric methods in pot culture. In this approach, the potgrown plants are covered with polythene bags to avoid direct evaporation and the pot weights are measured at the beginning and the end of the experiment to estimate the transpiration loss of each individual plant. The initial plant dry weight is measured at the beginning of the experiment using a different set of plants, and at the end of the experiment, the final plant dry weight is measured using some of the replicates (Krishnamurthy et al., 2007). WUE can be estimated using data on the amount of transpiration and the plant weight gain during the experiment. This method is already in use for groundnuts, and is simple and amenable to phenotyping of WUE in large-sized populations. Since this pot culture method does not permit natural root growth, the potential differences in WUE brought out by the deeper and shallower root systems of chickpea genotypes are expected to be masked. Certain improvements in the methodology to take into account differences in rooting depth are being tested, e.g., growing plants in deep cylinder systems. For pigeonpeas, the pot culture method has to be optimized because the root mass of this crop is expected to be much larger and deeper than that of chickpeas.

Carbon isotope discrimination $\left(\Delta^{13} \mathrm{C}\right)$ has been suggested as an indirect measure for WUE in many crops. Using this approach, Kashiwagi et al. (2006b) showed a clear relationship between WUE (obtained through a gravimetric method) and $\Delta^{13} \mathrm{C}$ under soil water deficit conditions. In this method, only a very small quantity (a few mg) of dried plant sample (e.g., leaf) is needed for the analysis using a sophisticated mass-spectrometer, and the samples can be kept stored for a long time. Therefore, it can potentially cope with large-scale phenotyping. For pigeonpeas, the $\Delta^{13} \mathrm{C}$ method would be more suitable because of the difficulties in estimating WUE gravimetrically using pot culture.

Osmotic adjustment could be increased to cope with the soil water deficit. It is the active accumulation of solutes in plant cells, as a result of which the water potential in the plant is decreased. OA has been shown to maintain photosynthesis and improve root growth and water extraction ability from the soil under drought conditions (Ludlow, 1980, 1987; Morgan and Condon, 1986). OA in chickpeas showed positive effects on seed yield under drought conditions (Morgan et al., 1991). Differences in OA observed in $\mathrm{F}_{8}$ progenies and parents have been shown to vary from year to year and have not consistently benefited seed yield in chickpeas under terminal drought, either in Australian or Indian locations (Turner et al., 2007). However, OA enhanced the seed yield in pigeonpeas under drought by delaying leaf senescence and improving the remobilisation of assimilates from the stems and leaves (Flower and Ludlow, 1986, 1987).

Membrane stability has been considered to be an indicator for improving drought tolerance (Gaff, 1980). In most crops, once dehydration has exceeded a critical threshold level, membrane function collapses leading to the death of the plant. However, in some crops, the membrane can be reconstituted and becomes functional within hours of well-watered conditions being provided. This membrane stability could, therefore, be considered as an important trait to contribute to improving plant growth under drought (Gaff, 1980). However, a clear relationship between crop performance under drought conditions and membrane stability has not been reported. It should be well understood before opening it up to large-scale phenotyping.

\section{PHENOTYPING TRAITS}

Of the available phenotypic screens, it appears that options for drought tolerance/resistance breeding in chickpeas and pigeonpeas are limited at present to selection for early maturity (drought escape) and root traits (drought avoidance). Both of the traits are easy to score, moderate (root trait) to high (earliness) in heritability, and variation for these characteristics is controlled by a few genes. For example, a single major gene controls flowering in chickpeas (Or et al., 1999; Kumar and van Rheenen, 2000). These two traits can also be scored easily in segregating populations 
to map QTLs associated with variation in flowering and root characteristics.

Like in chickpeas, earliness as a trait in pigeonpeas has also been used to select short or extra-short-duration lines that escape terminal drought, with a potential yield of about $2.5 \mathrm{t} \mathrm{ha}^{-1}$ (Nam et al., 1993). A deeper rooting system would also be a promising trait to improve soil water uptake from the subsoil, thereby improving drought tolerance in pigeonpeas.

Polyvinyl chloride pipe-based phenotypic screens for root traits have been well documented and can be used to screen large numbers of chickpea germplasm/breeding populations (Kashiwagi et al., 2005, 2006a). With some modification, the PVC pipe-based phenotyping of root traits can also be applied to screening for root characteristics in pigeonpeas.

\section{CONCLUSIONS}

The core and mini core collections in chickpeas and pigeonpeas, representing over $80 \%$ of the diversity present in the entire collection, should be evaluated for traits associated with drought tolerance under terminal drought stress conditions. Chickpea and pigeonpea reference sets, selected on the basis of genotyping results of the composite collections $(3,000$ and

\section{REFERENCES}

Brown, A. D. H. (1989). Core collections: a practical approach to genetic resources management. Genome 31, 818-824.

Chandra, S., Buhariwalla, H. K., Kashiwagi, J., Harikrishna, S., Rupa Sridevi, K., Krishnamurthy, L., Serraj, R., and Crouch, J. H. (2004). "Identifying QTL-linked markers in marker-deficient crops," in Proceedings of the Fourth International Crop Science Congress, eds T. Fischer, N. Turner, J. Angus, L. McIntyre, M. Robertson, A. Borrell, and D. Lloyd. Gosford, Australia: The Regional Institute Ltd.

Chauhan, Y. S., Saxena, N. P., and Johansen, C. (1992). "Abiotic factors limiting chickpea and pigeonpea production," in Proceedings of the National Symposium on New Frontiers in Pulses Research and Development, ed. J. N. Sachan. Kanpur, India: Directorate of Pulses Research, 111-123.

Chauhan, Y. S., Saxena, N. P., Rao, R. C. N., Johansen, C., and Ravindranath, K. (1997). Portable rainout shelter, a useful tool in drought research. ACIAR Food Legume Newsletter 25, 9.

FAO. (2010a). The State of World's Plant Genetic Resources for Food and Agriculture. Rome, Italy: FAO, 510.

FAO. (2010b). FAOSTAT: The Food and Agriculture Organization Corporate Statistical Database. Available at http://faostat.fao.org/site/567/ default.aspx\#ancor
Faris, D. G., and Singh, U. (1990). "Pigeonpea: nutrition and products," in The Pigeonpea, eds Y. L. Nene, S. D. Hall, and V. K. Sheila. Wallingford, UK: CAB International, 401-433.

Farquhar, G. D., O'Leary, M. H., and Berry, J. A. (1982). On the relationship between carbon isotope discrimination and intercellular carbon dioxide concentration in leaves. Aust. J. Plant Physiol. 9, 121-137.

Flower, D. J., and Ludlow, M. M. (1986). Contribution of osmotic adjustment to the dehydration tolerance of water-stressed pigeonpea (Cajanus cajan (L) Millsp) leaves. Plant Cell Environ. 9, 33-40.

Flower, D. J., and Ludlow, M. M. (1987). Variation among accessions of pigeonpea (Cajanus cajan) in osmotic adjustment and dehydration tolerance of leaves. Field Crops Res. 17, 229-243.

Frankel, O. H. (1984). “Genetic perspective of germplasm conservation," in Genetic Manipulations: Impact on Man and Society, eds W. Arber, K. Llimensee, W. J. Peacock, and P. Starlinger. Cambridge, UK: Cambridge University Press, 161-170.

Fukuoka, M. (2005). Improvement of a Method for Measuring Canopy Temperature in Field Crops Using an Infrared Thermograph. Ph.D. thesis, Hokkaido University, Sapporo, Japan, 1-45.

Gaff, D. F. (1980). "Protoplasmic tolerance to extreme water stress," in Adaptation of Plants to Water and

1,000 accessions respectively), should be evaluated for drought tolerance.

There is a need for further refinement of screening techniques and large-scale adoption of such techniques to select for traits associated with drought tolerance in breeding/mapping populations. There is also a need to saturate the mini core subset or reference set with an increased number of SSR and DArT markers to scan the whole genome and be used to detect marker-trait association using association genetics. The utility of leaf chlorophyll content as measured by Soil-Plant Analyses Development (SPAD) chlorophyll meter reading, WUE, OA, and leaf size and shape as a measure of drought tolerance need to be investigated further.

Early maturing pigeonpeas have a prolific but shallow root system. Consequently, there is a need to identify pigeonpea germplasm possessing early maturity and deep rooting. More attention is needed to understand marker-trait association in order to find PCR-based markers associated with drought tolerance to initiate marker-aided selection for traits associated with drought tolerance. Finally, there is a need to investigate the physiological basis of superior performance of pigeonpea hybrids under drought stress conditions.

High Temperature Stress, eds N. S. Turner and P. J. Kramer. New York, USA: John Wiley and Sons, 123-128. Gaur, P. M., Kumar, J., Gowda, C. L. L., Pande, S., Siddique, K. H. M., Khan, T. N., Warkentin, T. D., Chaturvedi, S. K., Than, A. M., and Ketema, D. (2008). "Breeding chickpea for early phenology: perspectives, progress and prospects," in Food Legumes for Nutritional Security and Sustainable Agriculture: Proceedings of the Fourth International Food Legumes Research Conference, ed. M. C. Kharkwal, Vol. 2. New Delhi, India: Indian Society of Genetics and Plant Breeding, 39-48.

Gaur, P. M., and Slinkard, A. E. (1990). Genetic control and linkage relations of additional isozyme markers in chickpea. Theor. Appl. Genet. 80, 648-653.

Hanks, R. J., Keller, J., Rasmussen, V. P., and Wilson, G. D. (1976). Line source sprinkler for continuous variable irrigation-crop production studies. Soil Sci. Soc. Am. J. 40, 426-429.

Hubick, K. T., Farquhar, G. D., and Shorter, R. (1986). Correlation between water-use efficiency and carbon isotope discrimination in diverse peanut (Arachis) germplasm. Aust. J. Plant Physiol. 13, 803-816.

Kashiwagi, J., Krishnamurthy, L., Crouch, J. H., and Serraj, R. (2006a). Variability of root length density and its contributions to seed yield in chickpea (Cicer arietinum L) under terminal drought stress. Field Crops Res. 95, 171-181.

Kashiwagi, J., Krishnamurthy, L., Singh, S. u. b. e., Gaur, P. M., Upadhyaya, H. D., Panwar, J. D. S., Basu, P. S., Ito, O., and Tobita, S. (2006b). Relationship between transpiration efficiency and carbon isotope discrimination in chickpea (Cicer arietinum L.). J. SAT Agric. Res. 2, 1-3.

Kashiwagi, J., Krishnamurthy, L., Upadhyaya, H. D., Krishna, H., Chandra, S., Vadez, V., and Serraj, R. (2005). Genetic variability of drought-avoidance root traits in the mini-core germplasm collection of chickpea (Cicer arietinum L). Euphytica 146, 213-222.

Khan, M. A. (1980). "Chickpea report from Pakistan," in Proceedings of the International Workshop on Chickpea Improvement (Hyderabad, India: ICRISAT), 258-263.

Krishnamurthy, L., Johansen, C., and Sethi, S. C. (1999). Investigation of factors determining genotypic differences in seed yield of nonirrigated and irrigated chickpea using a physiological model of yield determination. J. Agron. Crop Sci. 183, 9-17.

Krishnamurthy, L., Vadez, V., Jyotsna Devi, M., Serraj, R., Nigam, S. N., Sheshshayee, M. S., Chandra, S., and Aruna, R. (2007). Variation in transpiration efficiency and its related traits in a groundnut (Arachis hypogaea L) mapping population. Field Crops Res. 13, 189-197. 
Kumar, J., and Abbo, S. (2001). Genetics of flowering time in chickpea and its bearing on productivity in semiarid environments. Adv. Agron. 72, 107-138.

Kumar, J., and Rao, B. V. (1996). Super early chickpea developed at ICRISAT Asia Center. Int. Chickpea and Pigeonpea Newsletter 3, 17-18.

Kumar, J., and van Rheenen, H. A. (2000). A major gene for time of flowering in chickpea. J. Hered. 91, 67-68.

Loomis, R. S., and Connor, D. J. (1992). Crop Ecology: Productivity and Management in Agricultural Systems. Cambridge, UK: Cambridge University Press, 224-256.

Lopez, F. B., Johansen, C., and Chauhan, Y. S. (1994). Limitations to seed yield in short-duration pigeonpea under water stress. Field Crops Res. 36, 95-102.

Ludlow, M. M. (1980). “Adaptive significance of stomatal responses to water stress," in Adaptation of Plants to Water and High Temperature Stress, eds N. C. Turner and P. J. Kramer. New York, USA: John Wiley and Sons, 23-128.

Ludlow, M. M. (1987). "Contribution of osmotic adjustment to maintenance of photosynthesis during water stress," in Progress in Photosynthesis Research, ed. J. Biggins. Dordrecht, The Netherlands: Martinus Nijhoff, 161-168.

Morgan, J. M., and Condon, A. G. (1986). Water use, grain yield and osmoregulation in wheat. Aust. J. Plant Physiol. 13, 523-532.

Morgan, J. M., Rodriguez-Maribona, B. and Knights, E. J. (1991). Adaptation to water-deficit in chickpea breeding lines by osomoregulation: Relationship to grain-yields in field. Field Crops Res. 27, 61-70.

Murfet, I. C., and Reid, J. B. (1985). “The control of flowering and internode length in Pisum," in The Pea Crop: A Basis for Improvement, eds P. D. Hebblethwaite, M. C. Heath, T. C. K. Dawkins TCK. London, UK: Butterworths, 67-80.

Nadimpalli, R. G., Jarret, R. L., Phatak, S. C., and Kochert, G. (1994). Phylogenetic relationships of the pigeon pea (Cajanus cajan L) based on nuclear restriction fragment length polymorphism. Genome 36, 216-223.

Nam, N. H., Chauhan, Y. S., and Johansen, C. (1993). Comparison of extra-short-duration pigeonpea with short-season legumes under rainfed conditions on Alfisols. Exp. Agric. 29, 307-316.

Or, E., Hovav, R., and Abbo, S. (1999). A major gene for flowering time in chickpea. Crop Sci. 39, 315-322.

Pande, S., Kishore, G. K., Upadhyaya, H. D., and Rao, J. N. (2006). Identification of sources of multiple fungal diseases resistance in mini-core collection in chickpea. Plant Dis. 90, 1214-1218.

Panguluri, S. K., Janaiah, K., Govil, J. N., Kumar, P. A., and Sharma, P. C. (2006). AFLP fingerprinting in pigeonpea (Cajanus cajan (L) Millsp) and its wild relatives. Genet. Resour. Crop Evol. 53, 523-531.

Pfaff, T., and Kahl, G. (2003). Mapping of gene-specific markers on the genetic map of chickpea (Cicer arietinum L). Mol. Genet. Genomics 269, 243-251.

Pundir, R. P. S., Reddy, K. N., and Mengesha, M. H. (1988). ICRISAT Chickpea Germplasm Catalogue: Evaluation and Analysis. Patancheru, India: ICRISAT, 94.

Ratnaparkhe, M. B., Gupta, V. S., Murthy, M. R. V., and Ranjekar, P. K. (1995). Genetic fingerprinting of pigeonpea (Cajanus cajan (L) Millsp) and its wild relatives using RAPD markers. Theor. Appl. Genet. 91, 893-898.

Reddy, L. J., Upadhyaya, H. D., Gowda, C. L. L., and Singh, S. u. b. e. (2005). Development of core collection in pigeonpea (Cajanus cajan (L) Millsp) using geographic and qualitative morphological descriptors. Genet. Resour. Crop Evol. 52, 1049-1056.

Reddy, S. J., and Virmani, S. M. (1981). "Pigeonpea and its climatic environment," in Proceedings of the International Workshop on Pigeonpeas, Vol. 1. Patancheru, India: ICRISAT, 259-270.

Sandhu, S., Gupta, S. K., Gaur, P. M., Saxena, A. K., Sharma, S., and Kaur, P. (2007). "Studies on early podding varieties and post-harvest management of immature green grains of chickpea to be used as vegetable," in Proceedings of the First International Conference on Indigenous Vegetables and Legumes Prospectus for Fighting Poverty, Hunger and Malnutrition, eds M. L. Chadha, G. Kuo, and C. L. L. Gowda, Vol. 752. Acta Horticulturae (ISHS), 353-358. Available at http://www.actahort.org/books/752/ 752_61.htm

Saxena, K. B., Chauhan, Y. S., Kumar, R. V., Ariyanayagam, R. P., Srivastava, D. P., Johansen, C., and Asthana, A. N. (1997). "Heterosis breeding for higher yield in pigeonpea," in Recent Advances in Pulses Research, eds A. N. Ashtana and M. Ali. Kanpur, India: Indian Society of Pulses Research and Development, Indian Institute of Pulses Research, 109-125.

Saxena, N. P. (2003). "Management of drought in chickpea - a holistic approach", in Management of Agricultural Drought - Agronomic and Genetic Options, ed. N. P. Saxena. New Delhi, India: Oxford \& IBH Publishing Co Pvt Ltd, 103-122.

Serraj, R., Krishnamurthy, L., and Upadhyaya, H. D. (2004a). Screening of chickpea mini-core germplasm for tolerance to soil salinity. Int. Chickpea and Pigeonpea Newsletter 11 29-32.

Serraj, R., Krishnamurthy, L., Kashiwagi, J., Kumar, J., Chandra, S. and Crouch, J. H. (2004b). Variation in root traits of chickpea (Cicer arietinum L) grown under terminal drought. Field Crops Res. 88, 115-127.

Srivastava, N., Vadez, V., Upadhyaya, H. D., and Saxena, K. B. (2006). Screening for intra and interspecific variability for salinity tolerance in pigeonpea (Cajanus cajan) and its related wild species. J. SAT Agric. Res. 2, 1-12.

Subbarao, G. V., Chauhan, Y. S., and Johansen, C. (2000). Patterns of osmotic adjustment in pigeonpea its importance as a mechanism of drought resistance. Eur. J. Agron. 12, 239-249.

Subbarao, G. V., Johansen, C., Slinkard, A. E., Nageswara Rao, R. C., Saxena, N. P., and Chauhan, Y. S. (1995). Strategies for improving drought resistance in grain legumes. $C R C$ Crit. Rev. Plant Sci. 14, 469-523.

Tekeoglu, M., Rajesh, P., and Muehlbauer, F. J. (2002). Integration of sequence tagged microsatellite sites to the chickpea genetic map. Theor. Appl. Genet. 105, 847-854.

Than, A. M., Maw, J. B., Aung, T., Gaur, P. M., and Gowda, C. L. L. (2007). Development and adoption of improved chickpea varieties in Myanmar. J. SAT Agric. Res. 5, 1-3.

Turner, N. C. (1986). Crop water deficits: a decade of progress. $A d v$. Agron. 39, 1-51.

Turner, N. C., Abbo, S., Berger, J. D., Chaturvedi, S. K., French, R. J., Ludwig, C., Mannur, D. M., and Singh, S. J. (2007). Osmotic adjustment in chickpea (Cicer arietinum L) results in no yield benefit under terminal drought. J. Exp. Bot. 58, 187-194.

Upadhyaya, H. D. (2003). Geographical patterns of variation for morphological and agronomic characteristics in the chickpea germplasm collection. Euphytica 132, 343-352.

Upadhyaya, H. D., Bramel, P. J., and Singh, S. (2001). Development of a chickpea core subset using geographic distribution and quantitative traits. Crop Sci. 41, 206-210.

Upadhyaya, H. D., Dwivedi, S. L., Baum, M., Varshney, R. K., Udupa, S. M., Gowda, C. L. L., Hoisington, D. and Singh, S. (2008). Genetic structure, diversity, and allelic richness in composite collection and reference set in chickpea (Cicer arietinum L). BMC Plant Biol. 8, 106. doi:10.1186/1471-2229-8-106

Upadhyaya, H. D., Dwivedi, S. L., Gowda, C. L. L., and Singh, S. (2007a). Identification of diverse germplasm lines for agronomic traits in a chickpea (Cicer arietinum L) core collection for use in crop improvement. Field Crops Res. 100, 320-326.

Upadhyaya, H. D., Salimath, P. M., Gowda, C. L. L., and Singh, S. (2007b). New early-maturing germplasm lines for utilization in chickpea improvement. Euphytica 157, 195-208.

Upadhyaya, H. D., Furman, B. J., Dwivedi, S. L., Udupa, S. M., Gowda, C. L. L., Baum, M., Crouch, J. H., Buhariwalla, H. K., and Singh, S. (2006a). Development of a composite collection for mining germplasm possessing allelic variation for beneficial traits in chickpea. Plant Genet. Resour. 4, 13-19.

Upadhyaya, H. D., Reddy, L. J., Gowda, C. L. L., Reddy, K. N., and Singh, S. (2006b). Development of a mini core subset for enhanced and diversified utilization of pigeonpea germplasm resources. Crop Sci. 46, 2127-2132.

Upadhyaya, H. D., and Ortiz, R. (2001). A mini core subset for capturing diversity and promoting utilization of chickpea genetic resources. Theor Appl. Genet. 102, 1292-1298.

Upadhyaya, H. D., Pundir, R. P. S., Gowda, C. L. L., Reddy, K. N., and Singh, S. (2005). Geographical patterns of diversity for qualitative and quantitative traits in the pigeonpea germplasm collection. Plant Genet. Resour. 3, 331-352.

Varshney, R. K., Hoisington, D. A., Upadhyaya, H. D., Gaur, P. M., Nigam, S. N., Saxena, K. B., Vadez, V., Sethy, N. K., Bhatia, S., Aruna, R., Gowda, M. V. C., and Singh, N. K. (2007). "Molecular genetics and breeding of grain legume crops for the semi-arid tropics," in Genomics Assisted Crop Improvement, Vol. 2, eds R. K. Varshney and R. Tuberosa. Dordrecht, The Netherlands: Springer, 307-342.

White, J. W., Castillo, J. A., and Ehleringer, J. (1990). Associations between productivity, root growth 
and carbon isotope discrimination in Phaseolus vulgaris under water deficit. Aust. J. Plant Physiol. 17, 189-198.

William, P. C., and Singh, U. (1987). "Nutritional quality and the evaluation of quality in breeding programmes," in The Chickpea, eds M. C. Saxena and K. B. Singh. Wallingford, UK: CAB International, 329-356.

Winter, P., Benko-Iseppon, A. M., Huttel, B., Ratnaparkhe, M., Tullu, A., Sonnante, G., Pfaff, T., Tekeoglu, M., Santra, D., Sant, V. J., Rajesh, P. N., Kahl, G., and Muehlbauer, F. J. (2000). A linkage map of chickpea (Cicer arietinum L) genome based on recombinant inbred lines from a $\mathrm{C}$ arietinum $\times \mathrm{C}$ reticulatum cross: localization of resistance genes for
Fusarium wilt races 4 and 5. Theor. Appl. Genet. 101, 1155-1168.

Winter, P., Pfaff, T., Udupa, S. M., Huttel, B., Sharma, P. C., Sahi, S. Arreguin-Espinoza, R., Weigand, F., Muehlbauer, F. J., and Kahl, G. (1999). Characterization and mapping of sequence-tagged microsatellite sites in the chickpea (Cicer arietinum L) genome. Mol. Genet. Genomics 262, 90-101.

Wright, G. C., Hubick, K. T., and Farquhar, G. D. (1988). Discrimination in carbon isotopes of leaves correlates with water-use efficiency of field-grown peanut cultivars. Aust. J. Plant Physiol. 15, 815-825.

Wright, G. C., Nageswara Rao, R. C., and Farquhar, G. D. (1994). Water-use efficiency and carbon isotope discrimination in peanut under water deficit conditions. Crop Sci. 39, 92-97.

Yang, S., Pang, W., Ash, G., Harper, J., Carling, J., Wenzl, P., Huttner, E., Zong, X., and Kilian, A. (2006). Low level of genetic diversity in cultivated pigeonpea compared to its wild relatives is revealed by diversity arrays technology. Theor. Appl. Genet. 113, 585-595.

Conflict of Interest Statement: The authors declare that the research was conducted in the absence of any commercial or financial relationships that could be construed as a potential conflict of interest.

Received: 21 February 2012; accepted: 16 May 2012; published online: 01 June 2012.
Citation: Upadhyaya HD, Kashiwagi J, Varshney RK, Gaur PM, Saxena KB, Krishnamurthy L, Gowda CLL, Pundir RPS, Chaturvedi SK, Basu PS and Singh IP (2012) Phenotyping chickpeas and pigeonpeas for adaptation to drought. Front. Physio. 3:179. doi: 10.3389/fphys.2012.00179

This article was submitted to Frontiers in Plant Physiology, a specialty of Frontiers in Physiology.

Copyright (c) 2012 Upadhyaya, Kashiwagi, Varshney, Gaur, Saxena, Krishnamurthy, Gowda, Pundir, Chaturvedi, Basu and Singh. This is an open-access article distributed under the terms of the Creative Commons Attribution Non Commercial License, which permits noncommercial use, distribution, and reproduction in other forums, provided the original authors and source are credited. 